\title{
El control de convencionalidad y la protección de los derechos humanos en Colombia
}

\author{
Lizandro Cabrera*
}

* Magíster en Derecho. Coordinador de investigaciones, Facultad de Derecho, Universidad Cooperativa de Colombia, Cali, Colombia. Correo electrónico: lizandro.cabreras@campusucc.edu.co

Recibido: 25 de marzo de 2014 Aprobado: 5 de mayo de 2014

Cómo citar este artículo:

Lizandro Cabrera. El control de convencionalidad y la protección de los derechos humanos en Colombia. DIXI. Junio 2014. Pág. 53. doi: http://dx.doi. org/10.16925/di.v16i19.732

\begin{abstract}
Resumen
El Estado colombiano se ha comprometido al cumplimiento de los derechos humanos para adaptar las leyes ordinarias a los contenidos del bloque de constitucionalidad. Estas políticas deben diseñarse, regularse, escogerse y aplicarse a los derechos humanos consagrados en convenios y tratados internacionales ratificados por Colombia, de aquí la importancia del cumplimiento de las normas humanitarias por parte de la guerrilla. Por su parte, el Gobierno manifestó que, no habiendo ninguna posibilidad coactiva, ese sería el momento para que la guerrilla demostrara su voluntad de paz, dando cumplimiento a dichos preceptos, ya que es más fácil la solución política negociada del conflicto, mediante la concesión de un cese al fuego bilateral o tregua o, en su defecto, en desarrollo de una guerra regularizada por las normas del derecho internacional humanitario, toda vez que, en una guerra tan degradada como la que se ha venido desarrollando en Colombia, esto se hace más complejo. El presente trabajo de investigación se realiza desde la teoría dualista, por cuanto el artículo 93 de la Constitución Política de Colombia establece que los tratados y convenios internacionales ratificados por el Congreso, que reconocen los derechos humanos y que prohíben su limitación en los estados de excepción, prevalecen en el orden interno. Así como los derechos y deberes consagrados en la Carta se interpretarán según los tratados internacionales sobre derechos humanos ratificados por Colombia.
\end{abstract}

Palabras clave: bloque de constitucionalidad, control de convencionalidad, Corte Constitucional, derechos humanos, tratados internacionales, principios.

Control of Conventionality and Protection of Civil Rights in Colombia

\section{Abstract}

The Colombian State has committed itself to compliance on human rights in terms of adapting ordinary laws to the contents of the block of constitutionality. These policies must be designed, regulated, chosen and applied to the human rights enshrined in international agreements and treaties ratified by Colombia, thus the importance of compliance by the guerrillas with humanitarian norms. The government has stated that, lacking any possibility for coercion, now would be the time for the guerrillas to demonstrate their commitment to peace by complying with those precepts. That is because it would be easier to arrive at a negotiated political solution to the conflict by means of a bilateral cease-fire or truce, or, failing this, through a war regulated by the norms of international humanitarian law, because in a conflict as degraded as Colombia's, this becomes more complex. This research work is based on the dualistic theory, insofar as Article 93 of the Colombian Constitution establishes that international treaties and agreements ratified by the Congress, which recognize human rights and prohibit their limitation in states of emergency, prevail in the internal order. Thus the rights and duties enshrined in the Constitution shall be interpreted according to the international human rights treaties ratified by Colombia.

Keywords: block of constitutionality, control of conventionality, Constitutional Court, human rights, international treaties, principles. 
O CONTROLE DE CONVENCIONALIDAdE E A PROTEÇÃo DOS DIREITOS HUMANOS NA COLÔMBIA

Resumo

O Estado colombiano tem se comprometido com o cumprimento dos direitos humanos para adaptar as leis ordinárias aos conteúdos do bloco de constitucionalidade. Essas políticas devem ser desenhadas, reguladas, escolhidas e aplicadas aos direitos humanos consagrados em convênios e tratados internacionais ratificados pela Colômbia, por isso a importância do cumprimento das normas humanitárias por parte da guerrilha. Por sua vez, o Governo manifestou que, não havendo nenhuma possibilidade coativa, este seria o momento para que a guerrilha demonstrasse sua vontade de paz, dando cumprimento a esses preceitos, já que é mais fácil a solução política negociada do conflito, mediante a concessão de um cessar-fogo bilateral ou trégua ou, na sua falta, do desenvolvimento de uma guerra regularizada pelas normas do direito internacional humanitário; levando em consideração a guerra tão degradada que se tem desenvolvido na Colômbia, isso se faz mais complexo. O presente trabalho de pesquisa se realiza a partir da teoria dualista, por quanto o artigo 93 da Constituição Política da Colômbia estabelece que os tratados e convênios internacionais ratificados pelo Congresso, que reconhecem os direitos humanos e que proíbem sua limitação nos estados de exceção, prevalecem na ordem interna. Assim como os direitos e deveres consagrados na Carta se interpretarão segundo os tratados internacionais sobre direitos humanos ratificados pela Colômbia.

Palavras-chave: bloco de constitucionalidade, controle de convencionalidade, Corte Constitucional, direitos humanos, tratados internacionais, princípios.

\section{INTRODUCCIÓN}

El conflicto armado que viven los colombianos desde hace más de cinco décadas hace que las ofensivas guerrilleras y los operativos militares sean noticias, más que frecuentes, comunes. Aunque por excelencia, el mejor camino para alcanzar la paz es el diálogo, mientras continúe la guerra y las guerrillas insistan en la toma del poder por la fuerza, mediante la combinación de todas las formas de lucha, se hace necesario la aplicación del derecho internacional humanitario (DIH), para disminuir el impacto que genera en la población civil los atentados terroristas con carros y casas bomba, las masacres, el secuestro, el reclutamiento de niños y el uso de minas antipersonales. Para la comunidad internacional, Colombia es catalogado como uno de los países más violentos del mundo, teniendo los primeros lugares en el desplazamiento forzado y despojo de tierras, al lado de Sudan, Somalia y Siri Lanka, entre otros; $^{1}$ y lo que se pretende con la aplicación del derecho internacional humanitario es humanizar la guerra, lo que no implica resignarse a la existencia de un conflicto, sino tratar de evitar hechos violentos contra aquellos que no son agentes directos de la confrontación armada, generando espacios para el diálogo.

1. Véase Consultoría para los Derechos Humanos y el Desplazamiento (Codhes). Conferencia Regional Humanitaria (CRH) sobre la Protección de Personas Desplazadas y Refugiadas. Quito. (2010).
El enfrentamiento irregular ha durado mucho tiempo:

Han cambiado los actores, los escenarios y las formas; sin embargo, la conflagración ni ha restaurado la normalidad ni se acerca el día de su restablecimiento. La guerra hoy, como siempre, es una empresa onerosa. Tanto para el Estado colombiano para la insurgencia, los costos son cada vez más grandes.

Lo que explica que la insurgencia haya recurrido al secuestro, las vacunas y la presión sobre las grandes empresas nacionales y extranjeras, de aquí que los comportamientos hicieron surgir por reacción los grupos de autodefensa, dado que se argumentaba que el Estado no estaba en capacidad de garantizar la vida y los bienes de los ciudadanos. En ocasiones, estos grupos han contado con el apoyo de elementos de la fuerza pública en entrenamiento, logística, información y permisividad, circunstancia que ha dado pie para que se hable de grupos paramilitares. El modelo se experimentó a fondo en el Magdalena Medio, en que confluyeron antiguos simpatizantes de las Fuerzas Armadas Revolucionarias de Colombia (FARC), políticos, hacendados, narcotraficantes y elementos de la fuerza pública, en la organización de los grupos de autodefensa. Este modelo se extendió a otras regiones del país.

La política de exterminio asumida por la extrema derecha colombiana ha elevado los niveles de barba- 
rie de la violencia colombiana a límites insoportables. No solo se ataca a personas por separado, sino a grupos enteros. Las masacres se han venido sucediendo, una tras otra, en una espiral de retaliaciones que no parece tener fin. La población civil ha sido convertida en blanco principal de la acción bélica. En Urabá, por ejemplo, investigadores de derechos humanos señalan que por cada combatiente muerto eran asesinados veinte civiles. ${ }^{2}$

En general, en Colombia, hasta 1996, por cada combatiente muerto eran cuatro los civiles asesinados en razón del conflicto armado. La violencia ha impregnado todos los ámbitos de la vida nacional. Se pretende resolver cualquier problema por el uso de las armas. ${ }^{3}$

Las masacres que realizaron actores armados del conflicto que se vive en Colombia fueron documentadas y, en algunos casos, se le comunicó a la Comisión Interamericana de Derechos Humanos en Washington. Colombia es uno de los Estados que firmó el 22 de noviembre de 1969 la Convención Americana sobre Derechos Humanos (Pacto de San José de Costa Rica), ratificándola el 31 de julio de 1973 y aceptando la competencia contenciosa de la Corte Interamericana de Derechos humanos el 21 de junio de 1985, lo que implica:

reconocer la competencia de la Comisión Interamericana de Derechos Humanos por tiempo indefinido bajo condición de estricta reciprocidad y para hechos posteriores a esta aceptación, sobre casos relativos a la interpretación o aplicación de la Convención, reservándose el derecho de hacer cesar la competencia en el momento que lo considere oportuno. El mismo instrumento reconoce la competencia de la Corte Interamericana de Derechos Humanos por tiempo indefinido, bajo condición de reciprocidad y para hechos posteriores a esta aceptación, sobre casos relativos a la interpretación o aplicación de la Convención, reservándose el derecho de hacer cesar la competencia en el momento que lo considere oportuno.

\footnotetext{
2. Véase Consultoría para los Derechos Humanos y el Desplazamiento (Codhes). UN PAÍS QUE HUYE: DESPLAZAMIENTO Y VIOLENCIA EN UNA NACiÓn Fragmentada. Codhes - Unicef Colombia. (1999). Consultado el 12 de agosto de 2014 en http://www.acnur.org/biblioteca/pdf/5161. pdf?view=1

3. Fiscalía General de la Nación. Decisión de la Fiscalía 49 EsPeciaLIZADA UNDH - DIH CALIFICANDO DE CRIMEN CONTRA LA HUMANIDAd EL Secuestro De Jineth Bedoya. Septiembre 10, 2012.
}

La violación de derechos humanos, ya sea por parte del Estado, ya sea por un particular, implica responsabilidad internacional, por haber omitido la diligencia necesaria para prevenirla y no haberla investigado correctamente. Por ejemplo, el caso Paniagua Morales y otro contra Guatemala ilustran esta postura:

Para establecer que se ha producido una violación de los derechos consagrados en la Convención, no se requiere determinar, como ocurre en el derecho penal interno, la culpabilidad de sus autores o su intencionalidad y tampoco es preciso identificar individualmente a los agentes a los cuales se atribuyen los hechos violatorios. Es suficiente la demostración de que ha habido apoyo o tolerancia del poder público en la infracción de los derechos reconocidos en la Convención Americana. Además, también se compromete la responsabilidad internacional del Estado cuando éste no realiza las actividades necesarias, de acuerdo con su derecho interno, para identificar y, en su caso, sancionar a los autores de las propias violaciones. ${ }^{4}$

En las normas del derecho internacional, reguladoras de los derechos humanos, es frecuente la referencia a la dignidad de la persona humana. En ocasiones, la referencia se la caracteriza en forma de derecho; en el preámbulo de la Declaración Universal de los Derechos Humanos proclama su fe "en la dignidad y el valor de la persona humana" y determina que "todos los seres humanos nacen libres o iguales en dignidad y derechos y, dotados están de razón y conciencia, deben comportarse fraternalmente los unos con los otros". Esta, la de mayor trascendencia conocida por el género humano, se encontró con la falta de voluntad por cumplirla y la ausencia de instrumentos jurídicos eficaces para garantizar los derechos en ella contenidos. Con objeto de superar dichos problemas, vienen luego los pactos o tratados internacionales de derechos humanos. Esto tiene lugar en multitud de normas. Entre ellas pueden señalarse las siguientes:

El preámbulo de la Declaración Universal de los Derechos Humanos afirma en el primer considerando:

La libertad, la justicia y la paz en el mundo tienen por base el reconocimiento de la dignidad [...]; el quinto Considerando del Preámbulo afirma que: los pueblos de las Naciones Unidas han reafirmado en la Carta su fe en [...] la dignidad y el valor de la persona [...] El artículo

4. Corte Interamericana de Derechos Humanos. Sentencia del 8 DE marzo de 1998 (Fondo). Caso de la "Panel Blanca" (Paniagua Morales y otros) Vs. Guatemala. (8 de marzo de 1998). Disponible en http://www.corteidh.or.cr/docs/casos/articulos/seriec_37_esp.pdf 
primero de la Declaración Universal proclama que: todos los seres humanos nacen libres e iguales en dignidad [...]

La Declaración Americana de los Derechos y Deberes del Hombre afirma, en el considerando 1, que:

Los pueblos americanos han dignificado la persona humana [...]; el Considerando $2^{\circ}$ de la Declaración Americana dice que: [...] los Estados americanos han reconocido que los derechos esenciales del hombre no nacen del hecho de ser nacional de un determinado Estado, sino que tienen como fundamento los atributos de la persona humana.

El considerando 2 de la Declaración sobre la protección de todas las personas contra la tortura y otros tratos o penas crueles, inhumanas o degradantes, aprobada por la Asamblea General de las Naciones Unidas, en sesión del 9 de diciembre de 1975 afirma explícitamente: "Los Derechos Humanos: emanan de la dignidad inherente de la persona humana".

La Declaración Americana de Derechos y Deberes del Hombre, del 2 de mayo de 1948, se complementa con la Convención Americana de Derechos Humanos, aprobada en San José, Costa Rica, el 22 de noviembre de 1969, cuyo artículo 11.1 establece el principio esencial de que "toda persona tiene derecho al respecto de su honra y al reconocimiento de su dignidad".

Uno de los esfuerzos fundamentales que deben hacerse no es tanto saber cuáles y cuántos son estos derechos, cuál es su naturaleza y su fundamento, si son derechos naturales o históricos, absolutos o relativos, sino cuál es el modo más seguro para garantizarlos, para impedir que, a pesar de las declaraciones solemnes, sean continuamente violados. La obligación del Estado de garantizar los derechos le exige a este asegurar la eficacia práctica de los derechos humanos con todos los medios a su alcance, estableciendo instituciones y procedimientos formativos. Según la Corte Constitucional, ${ }^{5}$ siempre que se hable de bloque de constitucionalidad se hace referencia a cualquier norma que conforma a la Constitución y que exige su integración; por lo tanto, la violación de una norma que conforma este bloque de constitucionalidad constituye una violación al Estatuto Superior. Es así como en el artículo 93 de la Constitución Política de 1991 se con-

5. Corte Constitucional de Colombia. Sentencia C-225/95. (Mayo 8 de 1995). Disponible en www.corteconstitucional.gov.co/ relatoria/1995/c-225-95.htm [De aquí en adelante Corte Const. Col.] fiere rango constitucional a todos los tratados de derechos humanos ratificados por Colombia y relacionados con los derechos:

Los tratados y convenios internacionales ratificados por el Congreso, que reconocen los derechos humanos y que prohíben su limitación en los estados de excepción, prevalecen en el orden interno. Los derechos y deberes consagrados en esta Carta, se interpretarán de conformidad con los tratados internacionales sobre derechos humanos ratificados por Colombia.

En este artículo, se da la mayor apertura hacia el derecho internacional de los derechos humanos y se les entrega un plus del cual carecían en vigencia de la Constitución de 1886. Afirmar, como se hace en este artículo de manera categórica, que los tratados sobre derechos humanos ratificados por Colombia que prohíben su limitación en los estados de excepción prevalecen en el orden interno es dar un paso firme hacia adelante en la protección de los derechos y las libertades individuales y sentar las bases para la construcción de una nueva dogmática constitucional. Ese "prevalecen en el orden interno" no significa nada distinto de "tienen rango supralegal", es decir, constitucional, y forman con el articulado de la Constitución de 1991 un solo bloque. El bloque de constitucionalidad está compuesto por aquellas normas y principios que, sin aparecer formalmente en el articulado del texto constitucional, son utilizados como parámetros del control de constitucionalidad de las leyes, por cuanto han sido normativamente integrados a la Constitución, por diversas vías y por mandato de la propia Constitución. Son, pues, verdaderos principios y reglas de valor constitucional. El artículo 93 de la Carta es el único criterio interpretativo con rango constitucional expreso, y así se reitera en el artículo 4 del Decreto 2591 de 1991.

En este sentido, considera Bobbio que "el fundamento de los derechos humanos, a pesar de la crisis de los fundamentos, está, en cierto modo resuelto, con la proclamación de común acuerdo de una Declaración Universal de los Derechos del Hombre. Se trata de un fundamento histórico y, como tal, no absoluto: pero el histórico del consenso es el único fundamento que puede ser probado factualmente".

6. Corte Constitucional de Colombia. Sentencia No. T-0o2/92. (Mayo 8 de 1992). Disponible en http://www.corteconstitucional.gov.co/ relatoria/1992/t-002-92.htm\# ftn6 
Como si fuera poco, el inciso 2 de la norma establece en cita que los derechos y deberes consagrados en esta Carta se interpretarán según los tratados internacionales sobre derechos humanos ratificados por Colombia. De acuerdo con esto, no solo tienen aplicación directa y prevalente, sino que, además, sirven de carácter interpretativo. El desarrollo de este precepto, según se verá más adelante, se da mediante la aplicación de la jurisprudencia de los tribunales internacionales de derechos humanos, por ser esta la que nos enseña el sentido y alcance de estos tratados para poder interpretar nuestras normas internas según ellos.

El artículo 94 es contentivo de la cláusula de los derechos innominados o inherentes, como los llama la Constitución. El artículo dice: "La enunciación de los derechos y garantías contenidos en la Constitución y en los convenios internacionales vigentes, no debe entenderse como negación de otros que, siendo inherentes a la persona humana, no figuren expresamente en ellos". Fue tomado de la Novena Enmienda a la Constitución de Filadelfia, y es el fundamento de la Sentencia T-002 de 1992, el primer fallo en el que se empezó a hacer uso de la figura del bloque de constitucionalidad en el derecho colombiano. Mediante ella se abre la posibilidad para que los jueces, usando la acción de tutela, introduzcan en el ordenamiento constitucional derechos que no figuran ni en la Constitución ni en los tratados sobre derecho humanos. Se abre, de esta manera, el texto superior hacia un catálogo infinito de libertades no positivas que tendrían el rango de libertades y garantías constitucionales.

La Corte Constitucional, en consecuencia, mediante Sentencia T-708 de 2003, ha señalado:

Es que el concepto de dignidad humana no constituye hoy, en el sistema colombiano, un recurso literario u oratorio, ni un adorno para la exposición jurídica, sino un principio constitucional, elevado al nivel de fundamento del Estado y base del ordenamiento y de la actividad de las autoridades públicas.

En virtud de la dignidad humana se justifica la consagración de los derechos humanos como elemento esencial de la Constitución Política (art. 1 C.P.) y como factor de consenso entre los Estados, a través de las cláusulas de los tratados públicos sobre la materia (art. 93 C.P.).

La dignidad de la persona se funda en el hecho incontrovertible de que el ser humano es, en cuanto tal, único en relación con los otros seres vivos, dotado de la racionalidad como elemento propio, diferencial y específico, por lo cual excluye que se lo convierta en medio para lograr finalidades estatales o privadas, pues, como lo ha repetido la jurisprudencia, la persona es "un fin en sí misma".

Pero, además, tal concepto, acogido por la Constitución, descarta toda actitud despectiva frente a sus necesidades corporales y espirituales, todas las cuales merecen atención en el Estado social de derecho, que reconoce en el ser humano la razón de su existencia y la base y justificación del sistema jurídico.

Todo lo anterior implica que la dignidad de la persona humana, como valor fundamental y parte dogmática de los derechos humanos, se ha ido mediatizando. Así es como los derechos derivados del reconocimiento de la dignidad del hombre (libertad, igualdad, honor, intimidad, vida, integridad, etcétera), si bien se encuentran reconocidos y proclamados, no son respetados en la vida del hombre con la asiduidad que desearíamos, produciéndole un atropello continuo y progresivo a su dignidad.

La Constitución no crea esos derechos porque la dignidad del ser humano existe con Constitución o sin ella, y aun contra ella. Sólo los reconoce y protege, es decir que los derechos humanos son inherentes a la naturaleza humana. El hombre nace con ellos, por tanto, la justicia que viola la dignidad humana no es justicia. La dignidad de la persona humana es el valor básico que fundamenta los derechos humanos, ya que su afirmación no solo constituye una garantía de tipo negativo que protege a las personas contra vejámenes y ofensas de todo tipo, sino que debe también afirmar positivamente a través de los derechos el pleno desarrollo de cada ser humano y de todos los seres humanos, situación que se dio en la Segunda Guerra Mundial: los pueblos inician la etapa de convivencia pacífica, la que tiene como su fundamento la dignidad de la persona humana, tal como lo declararon los Estados reunidos en la Conferencia de San Francisco de 1945, que aprobaron la resolución de "reafirmar la fe en los derechos fundamentales del hombre, en la dignidad y el valor de la persona humana, en la igualdad de derechos de hombres y mujeres, y de las naciones grandes y pequeñas".

La Asamblea General de las Naciones Unidas, del 10 de diciembre de 1948, constituye el primer texto de

7. Corte Constitucional de Colombia. Sentencia T-708/03. (Agosto 14 de 2003). Disponible en http://www.corteconstitucional.gov.co/ relatoria/2003/T-708-03.htm

8. Naciones Unidas. Preámbulo. Carta de las Naciones Unidas. 1945. Disponible en http://www.un.org/es/documents/charter/preamble.shtml 
alcance universal reconocedor de la dignidad de la persona y los derechos esenciales o fundamentales que derivan de ella.

\section{REFERENTES TEÓRICOS}

El derecho internacional humanitario corresponde a una de las ramas del derecho público, y sus teorías son estas: teoría monista, que se subdivide en monista internacionalista y monista nacionalista; teoría dualista o pluralista, y teoría de la prevalencia del derecho internacional público sobre el derecho interno. ${ }^{9}$

La teoría monista fue desarrollada por Kunz, Lauterpach, Verdross ${ }^{10}$ y, principalmente, por Hans Kelsen. ${ }^{11}$ La teoría monista internacionalista pregona la unidad de todas las ramas jurídicas en un solo sistema, la cual parte de la concepción normativista de Kelsen según la cual todas las normas jurídicas derivan su validez y su obligatoriedad de otras normas superiores hasta llegar a la norma fundamental, en que la norma de mayor jerarquía podía encontrarse tanto en el derecho interno como en el derecho internacional, ubicándola posteriormente en este último. Luego, la atribución legisladora de los Estados se encontraba sujeta a las normas del derecho internacional público por cuanto el derecho interno de los Estados estaba subordinado al derecho internacional, incluso sin el requisito previo de un acto de incorporación especial. ${ }^{12}$ Básicamente, Kelsen en su concepción radical expresa que toda norma interna opuesta a una norma internacional queda automáticamente derogada, por cuanto se recoge la Convención de Viena sobre los tratados de 1969, que en su artículo 27 establece:

9. Véase Ramón Pacheco Sánchez. InTERRelación entre NORMAS DEL DERECHO INTERNACIONAL PÚBLICO Y EL DERECHO INTERNO. ESTATUS PREVALENTE DE NORMA IUS CONGENS. (Febrero 26 de 2012). Disponible en http://derechointernacionaluniversidadlibre.blogspot.com/2012/02/ interrelacion-entre-normas-del-derecho.html

10. Alfred Verdross (1890-1980). Profesor y tratadista austriaco. Destacado jurista en el campo del Derecho Internacional Público y en Filosofía del Derecho. Profesor y decano de la Facultad de Derecho de la Universidad de Viena, discípulo de Hans Kelsen.

11. Hans Kelsen (Praga, 11 de octubre de 1881 - Berkeley, California, 19 de abril de 1973) fue jurista, político y filósofo del derecho austríaco, de origen judío.

12. Véase Pacheco, supra, nota 9.
Un Estado no puede invocar las disposiciones del derecho interno como justificación del incumplimiento de los tratados, salvo lo dispuesto en el artículo 46, que prevé que sólo procede la nulidad de un tratado opuesto a derecho interno cuando la violación a una norma fundamental de este sea manifiestamente evidente. ${ }^{13}$

Es decir, la tesis imperante en el derecho internacional es la prevalencia de este sobre el derecho interno. A contrario sensu, en la teoría monista nacionalista se considera que el derecho estatal está por encima del derecho internacional público, por lo que ninguna norma que lo contraríe se puede aplicar. ${ }^{14}$

Algunas legislaciones proclaman por la superioridad del derecho interno sobre el derecho internacional, o defienden políticamente su aplicación de acuerdo con sus conveniencias o sus intereses, invocan el derecho internacional para exigirles a otros Estados la protección de los derechos humanos, y hasta han creado sistemas de certificación para condicionar la cooperación y el apoyo financiero a sus aliados que no satisfacen sus requerimientos políticos. ${ }^{15}$ También se arguye que, si la voluntad del Estado es suficiente para concebir el derecho internacional, este sería un derecho estatal externo, como lo sostiene Anziolitti, quien dice que solo "serían relaciones entre dos categorías de normas internas". ${ }^{16}$

El dualismo o pluralismo parte de las hipótesis que emergen de las circunstancias de tiempo, modo y lugar de generación y aplicación de la norma, por un lado, y por otro, el derecho internacional y el derecho interno de los Estados que constituyen ordenamientos jurídicos independientes, en que por ser distinto el fundamento de su existencia, y ser diferente su forma de creación, y ser sujetos o instituciones distintas a quienes va dirigido, esto es, en el derecho interno o estatal se remite a gobernantes y a gobernados, y en el derecho internacional a los sujetos típicos, como los Estados, o a los sujetos atípicos del derecho internacional público, como las organizaciones internacionales. ${ }^{17}$ Dicho de otra manera, la teoría dualista o pluralista se fundamenta en

13. Ley 32 de 1985. Por la cual se aprueba la Convención de Viena sobre el Derecho de los Tratados. Febrero 13 de 1985. DO N. ${ }^{\circ} 36.856$.

14. Loretta Ortiz Ahlf. Derecho internacional público. UNAM Harla. (1988). Pág. 6.

15. Antonio Truyol y Serra. Fundamentos Del Derecho InTERnaCio-

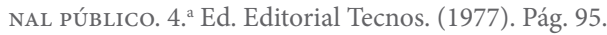

16. Véase Pacheco, supra, nota 9.

17. Id. 
que las normas de ambos ordenamientos proceden de fuentes distintas y se encuentran dirigidas a sujetos diferentes. A partir de estos conceptos, el derecho internacional requiere un acto especial, una ratificación que lo incorpore al derecho interno, adquiriendo a partir de ese acto el carácter de derecho interno.

La teoría coordinadora o conciliadora, que parte de la unidad de las distintas ramas jurídicas en un solo sistema, pero no acepta que las relaciones entre el derecho internacional y el interno sean de subordinación del segundo al primero, sostiene que, en realidad, entre ambos sistemas, se establecen relaciones de coordinación. Según Verdross, esta teoría la fundamentan Miaja de la Muela, Truyol y Luna, principalmente, entre otros autores.

La teoría de la prevalencia del derecho internacional público sobre el derecho interno se basa en que los Estados han acordado, a través de la Convención de Viena sobre los Tratados de 1969, ratificada por Colombia mediante la Ley 32 de 1985, que no se pueden invocar disposiciones del derecho interno de los Estados como justificación del incumplimiento de los tratados, salvo que se trate de declarar la nulidad de un tratado opuesto al derecho interno cuando la violación a una norma fundamental de este sea manifiesta y evidente. ${ }^{18}$ Vale la pena destacar que Colombia, mediante la Ley 288 de 1996, por medio de la cual se establecen instrumentos para la indemnización de perjuicios a las víctimas de violaciones de derechos humanos, se comprometió a pagar las indemnizaciones por las decisiones de organismos internacionales, estableciendo un mecanismo expedito para la pronta reparación del daño causado. ${ }^{19}$

En ese sentido, la Corte Constitucional ha manifestado:

De igual forma, resulta primordial señalar, para efectos del asunto bajo examen, lo dispuesto en el artículo $9^{\circ}$ superior, según el cual las relaciones exteriores del Estado se basan "en el reconocimiento de los principios del derecho internacional aceptados por Colombia”. Esta máxima fundamental — consagrada así por el Constituyente- significa ni más ni menos que nuestro

18. Naciones Unidas. Convención de Viena sobre el Derecho de Los Tratados. (Mayo 23 de 1969). Art. 27.

19 Ley 288 de 1996. Por medio de la cual se establecen instrumentos para la indemnización de perjuicio a las víctimas de violaciones de derechos humanos en virtud de lo dispuesto por determinados órganos internacionales de Derechos Humanos. Julio 05 del 1996. DO N. ${ }^{\circ} 42826$ de julio 09 de 1996. Arts. 2-4. país se acoge en un todo a los principios del derecho internacional que han sido aceptados, no sólo dentro de los parámetros de los tratados públicos ya sean éstos bilaterales o multilaterales, o de los acuerdos suscritos dentro del marco de los organismos internacionales a los cuales el Estado ha adherido - en particular, la Organización de la Naciones Unidas, ONU—, sino también a aquellos que se derivan de los usos y costumbres internacionalmente consagrados. ${ }^{20}$

\section{EL BLOQUE DE CONSTITUCIONALIDAD Y EL CONTROL DE CONVENCIONALIDAD}

\section{A. Experiencia estadounidense}

Al contrario a lo que muchos opinan, la teoría del bloque de constitucionalidad tiene su origen en el derecho estadounidense y no en el derecho francés. ${ }^{21} \mathrm{El}$ antecedente más remoto está en la Novena Enmienda a la Constitución de Filadelfia de 1787, la cual estableció la cláusula de los derechos innominados ${ }^{22}$ mediante la cual los jueces podían reconocer la existencia de derechos y libertades que no figuraran expresamente en el texto constitucional. El texto de esta enmienda, de la cual se tomó la referencia para la redacción del actual artículo 94 constitucional, es el siguiente: "Artículo IX. No por el hecho de que la Constitución enumera ciertos derechos ha de entenderse que niega o menosprecia otros que retiene el pueblo". Por esta vía, se amplió ilimitadamente el catálogo de derechos y libertades y, por consiguiente, el número de cláusulas constitucionales ahora extratexto. En desarrollo de esta figura, la Corte Suprema de Justicia de los Estados Unidos ha

20. Corte Constitucional de Colombia. Sentencia C-170/95. (Abril 20 de 1995). Disponible en http://www.corteconstitucional.gov.co/ relatoria/1995/C-170-95.htm

21. En este instante, es pertinente aclarar que la teoría tiene origen en los Estados Unidos, pero que la denominación "bloque de constitucionalidad" sí es de origen francés.

22. En dicha cláusula, se fundamentó el constituyente de 1991 para consagrar el artículo 94, el cual, en su redacción, es prácticamente igual. 
reconocido derechos, como el del debido proceso sustantivo ${ }^{23}$ y el derecho de las mujeres a abortar, ${ }^{24}$ por citar solo unos ejemplos.

\section{B. La postura del Consejo Constitucional Francés}

El Consejo Constitucional, al que se le debe el enorme desarrollo teórico de la teoría del bloque en el derecho europeo, ha tenido una postura que puede calificarse de audaz y prudente a la vez. Audaz porque se atrevió a incursionar en la figura y a aplicarla en un contexto en el que precisamente el control constitucional era débil. ${ }^{25}$ Prudente porque en cada decisión el uso de esta figura ha sabido sustentar debidamente su postura y asentarla en los ideales sociales y políticos del pueblo francés.

La inserción de esta teoría en el derecho francés se da con la decisión del 16 de julio de 1971 del Consejo Constitucional relativa a la libertad de asociación. En este fallo, el alto tribunal se pregunta si la Constitución de 1958, conocida como la Constitución de la V República Francesa, se compone únicamente del articulado formal, o si existen otras normas que hagan parte de la Constitución, sirvan como parámetro para el control de constitucionalidad de las leyes y no se hallen insertas en el texto. Frente a este interrogante, el Consejo se responde que, como quiera que el preámbulo de la Constitución contenga los principios y valores del ordenamiento francés, viene a hacer parte de la Constitución y, por ende, resulta vinculante. Además que, al hacer referencia el preámbulo a otras normas de la his-

23. Véase Louis Favoreu y Francisco Rubio Llorente. EL BLOQUE DE Constitucionalidad. Civitas. (1991). Pág. 44. En el caso Lochner de 1905, la Corte Suprema de Justicia conceptúa que la previsión de un límite en la jornada laboral vulnera la libertad contractual de las personas y eso contraría la Constitución. De manera concreta, la Corte Suprema de Justicia rechazó la afirmación del estado de Nueva York de que el límite de la jornada laboral en las panaderías estaba significativamente relacionado con la salud del empleado y afirmó que no hay dudas de que la ocupación de panadero no afectaba la salud "hasta el punto de autorizar al poder legislativo a interferir con el derecho a trabajar y con el derecho a contratar libremente". En ese sentido, no le estaba dado al legislativo interferir en las horas de trabajo y la remuneración que por ello recibe.

24. Id. Roe vs. Wade.

25. Manuel Cepeda. Los derechos fundamentales en la ConstituCIÓN DE 1991. Editorial Temis S. A. (1997). Recordemos que precisamente es en las últimas décadas en las que el Consejo Constitucional se ha hecho protagonista en una sociedad con tradición democrática muy fuerte, en la que el legislador goza de enorme aceptación y el control de la ley se asimila a controlar al pueblo soberano, sumado al hecho de que el control es previo y rogado. El autor prefiere hablar de inserción y no de surgimiento porque, como se acaba de mostrar, la teoría tiene su origen en el derecho estadounidense y no en el derecho francés, como algunos erróneamente afirman. toria constitucional francesa, estas normas hacen parte de la Constitución por la remisión directa o indirecta que a ellas se hace. Normas que componen el bloque de constitucionalidad en el derecho constitucional francés. Las normas que, a juicio del Consejo, hacen parte de la Constitución de 1958, son las siguientes: 1) el articulado de la Constitución, 2) el preámbulo de la Constitución de $1958,{ }^{26} 3$ ) la Declaración de los Derechos del Hombre y del Ciudadano de la Revolución Francesa de 1789, 4) el preámbulo de la Constitución de 1946, conocida como la Constitución de la IV República Francesa, ${ }^{27}$ 5) los principios fundamentales reconocidos por las leyes de la República hasta antes de la Constitución de 1946 y 6) los principios generales del derecho de valor constitucional.

La Revolución francesa dio origen al Estado moderno, el cual se constituyó como la organización jurídico-política capaz de responder a requerimientos y necesidades de la sociedad, promoviendo los mecanismos de participación democrática más amplios, en otras palabras, que fuera una constitución más social, democrática y ciudadana, bajo los principios y derechos enmarcados en tratados y convenios internacionales; es en este estadio en que se desarrolla la teoría de bloque de constitucionalidad. Este concepto tiene su origen en la práctica del Consejo Constitucional Francés, el cual considera que, como el preámbulo de la Constitución de ese país hace referencia al preámbulo de la Constitución derogada de 1946 y a la Declaración de Derechos del Hombre y del Ciudadano de 1789, esos textos son también normas y principios de valor constitucional que condicionan la validez de las leyes.

\section{Fundamentos CONSTITUCIONALES PARA LA RECEPCIÓN DE LA TEORÍA DEL BLOQUE DE CONSTITUCIONALIDAD EN Colombia}

La Constitución Política colombiana de 1886, que al decir de algunos carecía de fundamentos claros para la recepción de la teoría del bloque de constitucio-

\footnotetext{
26. Esta no es una consideración gratuita porque en muchos ordenamientos, el colombiano por ejemplo, hasta antes de la Constitución de 1991, el preámbulo no hace parte de la Constitución o no es vinculante.

27. Las expresiones IV o V República en el lenguaje constitucional se deben a que en Francia cada una de las constituciones de su historia republicana, que hasta ahora son cinco, han establecido un sistema político muy particular que la diferencia de la anterior, de ahí la clasificación.
} 
nalidad en el actual ordenamiento, es rica en fundamentos normativos para tal acción. Esta situación facilitó que la Corte Constitucional, ente encargado de la guarda de la integridad y supremacía de la Carta en el actual ordenamiento superior, si bien en un principio vacilante, tomara la decisión de hacer uso de esta figura en defensa, principalmente, de los derechos fundamentales.

Los solos fundamentos normativos no bastan para que una teoría sea recepcionada en un contexto, sino que es necesaria la acción de los operadores judiciales. En la Constitución de 1886, la oportunidad estuvo dada en varias ocasiones, pero la Corte Suprema de Justicia se negó a dar aplicación a esta figura e, incluso, a entrar en la discusión. La Corte Constitucional, al contrario, haciendo gala de una jurisprudencia progresista y altamente protectora de los derechos humanos, se aventuró en nuevos rumbos e hizo fino uso de las herramientas que la Constitución de 1991 le proporcionaba: aquí los fundamentos normativos para la recepción de la teoría del bloque de constitucionalidad en el derecho colombiano.

En Colombia, en vigencia de la Constitución de 1886, se consideraba que el preámbulo, al no hacer parte del articulado, no era vinculante. Se creía que era un conjunto de principios y valores de orden sociocultural y no jurídico que carecía de poder jurídico. En este mismo sentido, se pronuncia Favoreu:

A diferencia de lo que sucede en España, la noción de Bloque de Constitucionalidad no es una noción jurisprudencial, puesto que el Consejo Constitucional no la utiliza en sus decisiones. Se refiere, generalmente, a los principios de valor constitucional para designar las normas no inscritas en los textos constitucionales. ${ }^{28}$

La doctrina más autorizada en el derecho colombiano ha expresado que la noción de bloque constitucionalidad, ${ }^{29}$ originaria del derecho francés, alude a "la existencia de normas constitucionales que no aparecen directamente en el texto constitucional". Por su parte, la Corte Constitucional colombiana, conceptúa la noción de bloque como el conjunto de normas que hacen parte de la Constitución, pero que están

28. Véase Favoreu y Rubio, supra, nota 23. Pág. 48.

29. En Colombia, se ha acuñado con gran fuerza el concepto de bloque de constitucionalidad, en lugar de principios y reglas de valor constitucional. formalmente fuera de ella, es decir, fuera del texto constitucional. En tal sentido, dice la Corte:

La Corte considera que la noción de "Bloque de Constitucionalidad", proveniente del Derecho Francés pero que ha hecho carrera en el Derecho Constitucional Comparado permite armonizar los principios y mandatos aparentemente en contradicción de los artículos $4^{\circ}$ y 93 de nuestra Carta. Este concepto tiene su origen en la práctica del Consejo Constitucional Francés, el cual considera que, como el Preámbulo de la Constitución de ese país hace referencia al Preámbulo de la Constitución derogada de 1946 y a la Declaración de Derechos del Hombre y del Ciudadano de 1789, esos textos son también normas y principios de valor constitucional que condicionan la validez de las leyes. Según la doctrina francesa, estos textos forman entonces un Bloque con el articulado de la Constitución, de suerte que la infracción por una ley de las normas incluidas en el Bloque de Constitucionalidad comporta la in-exequibilidad de la disposición legal controlada. Con tal criterio, en la decisión del 16 de julio de 1971, el Consejo Constitucional anuló una disposición legislativa por ser contraria a uno de los "principios fundamentales de la República" a que hace referencia el Preámbulo de $1946 .{ }^{30}$

Los convenios internacionales son válidos cuando son ratificados por el país Estado parte, y dan paso al control de convencionalidad.

\section{Control de CONVENCIONALIDAD}

La dignidad humana se encuentra literalmente expresada en la Carta Magna colombiana en diversas disposiciones, así se tiene ya en la primera manifestación de los constituyentes. De aquí que la importancia de la defensa de la persona humana y el respeto de su dignidad son el fin supremo de la sociedad y del Estado, conviértase así en la primera finalidad de la elaboración de esa ley fundamental. Asimismo, la defensa de la vida es de carácter inviolable, que es la característica atribuida por la tendencia jurídica contemporánea, garantizar su respeto, dando prioridad a los miembros de los poderes públicos, quienes están obligados a respetar y proteger los derechos y deberes, consecuentemente de su

30. Rodrigo Uprimny Yepes. El bloque de constitucionalidad en Colombia. Un análisis jurisprudencial y un ensayo de sistematización doctrinal. Dejusticia. Diciembre 12 de 2005. Pág. 17. Disponible en http://www. dejusticia.org/files/r2_actividades_recursos/fi_name_recurso.46.pdf 
regulación normativa, constituyendo, por eso mismo, el supremo valor de nuestro régimen político, de modo que el Estado se halla al servicio de la persona humana y no la persona al servicio del Estado, por cuanto se considera que el hombre es un ser que tiene fines propios que cumplir. Asimismo, los derechos implícitos y de forma programática que se expresan en el texto constitucional, de todos estos aspectos, encuentran vinculación directa con lo que debemos entender por dignidad humana, los distintos aspectos que comprende, las condiciones dignas en la realización de su trabajo, garantizarle jornadas limitadas que redundan en una mejor calidad de vida, constituyendo todos estos distintos aspectos que en forma indirecta encuentran su fundamento en la dignidad que a todo ciudadano le es reconocida por su sola condición de persona. Es importante comprender el significado de la expresión principios de humanidad, sinónima de leyes de la humanidad. En la primera versión de la cláusula de Martens (preámbulo, II Convenio de La Haya de 1899) se dice "leyes de la humanidad"; para la última versión (protocolo adicional I) se emplea "principios de humanidad". Los principios de humanidad se interpretan en el sentido de que prohíben los medios y métodos de hacer la guerra que no sean necesarios para obtener una ventaja militar definitiva.

Jean Pictet interpreta el concepto de humanidad en el sentido de que

la humanidad exige que se prefiera la captura a la herida, la herida a la muerte, que, en la medida de lo posible, no se ataque a los no combatientes, que se hiera de la manera menos grave a fin de que el herido pueda ser operado y después curado y de la manera menos dolorosa, y que la cautividad resulte tan soportable como sea posible. ${ }^{31}$

La Sentencia C-225 de 1995 marcó una pauta jurídica y política, revolucionando la concepción del derecho internacional humanitario, no solo en Colombia sino en el ámbito internacional. El 16 de diciembre de 1994, mediante la Ley 171 de 1994, el Congreso colombiano aprobó el texto del protocolo adicional II, el presidente de la República procedió a sancionar la correspondiente ley y la Corte Constitucional, en su sentencia del 18 de mayo de 1995, encontró el mencionado instrumento internacional, así como su ley aprobato-

31. Jean Pictet. Desarrollo y principios del Derecho internacioNal humanitario. Instituto Henry Dunant. (1986). Pág. 74. ria, conforme a la normativa constitucional. Lo anterior marca una pauta de gran interés en el desarrollo del conflicto armado interno y la aplicación material del derecho internacional humanitario.

La mencionada sentencia presenta un análisis del protocolo II y del artículo 3 común. También nos habla de temas sensibles, como el temido reconocimiento de beligerancia, el carácter obligatorio de las normas contenidas en los tratados internacionales, reafirma que dichas normas no van en contravía de la soberanía nacional y la integración de las normas de derecho internacional humanitario, el llamado bloque de constitucionalidad. ${ }^{32}$ Antes de entrar al análisis realizado por la Corte Constitucional, es preciso citar a José Eduardo Umaña Mendoza, quien interviene y analiza la constitucionalidad del protocolo II de 1977.

El tratadista Alejandro Ramelli Arteaga manifiesta:

Se dio así un importante paso hacia la humanización de las hostilidades mediante la aceptación de un catálogo elemental de normas que se encuentran en la consciencia colectiva de la comunidad internacional como expresión de un límite de la racionalidad a la barbarie.

En esta medida, concluye:

Coincide totalmente el instrumento internacional con la Constitución Política, tal como Ustedes lo consideraron en su momento acerca, del Protocolo I, como quiera que está orientado el que ahora se somete a examen, a proteger la integridad de la población civil y salvaguardar la dignidad humana en las circunstancias de una guerra, existiendo al tiempo todo un conjunto de principios en el que, artículo tras artículo en ese catálogo de la Carta, se ordena en esencia lo mismo, por ejemplo, en lo relativo a la protección consignada de manera especial para los niños, para los indefensos, para la conservación de lo nuclear de la familia, prohibiéndose v. gr. los tratos inhumanos, degradantes o crueles y los atentados a la vida. ${ }^{33}$

32. Según la Corte Constitucional, el bloque de constitucionalidad está compuesto por aquellas normas y principios que, sin aparecer formalmente en el articulado del texto constitucional, son utilizados como parámetros de control de constitucionalidad de las leyes, por cuanto han sido normativamente integrados a la Constitución. Son pues verdaderos principios y reglas de valor constitucional, esto es, son normas situadas en el nivel constitucional, a pesar de que puedan a veces contener diversos mecanismos de reformas a los de las normas del articulado constitucional stricto sensu.

33. Véase Corte Const. Col., supra, nota 5. 
El catálogo de principios y derechos que tiene el derecho internacional humanitario realza su importancia en el convulsionado presente, y la necesidad de la aplicación de sus normas es un imperativo político, jurídico, moral y ético. Su estudio y puesta en práctica es y será una deuda que debemos cumplir con nuestra sociedad futura.

Las diferentes organizaciones gubernamentales y no gubernamentales que participan en el análisis de aprobación del protocolo II merecen ser citadas en el presente trabajo, puesto que demuestran que, para esta época, nuestro país estaba registrando importantes cambios para la humanización del conflicto. En su concepto de rigor, el procurador general de la nación solicita declarar constitucional el protocolo II, así como la Ley 171 de 1994 que aprueba ese instrumento internacional. Es importante la apreciación del procurador en la medida que señala:

El artículo $3^{\circ}$ común contiene un estatuto mínimo de Derechos Humanos - de normas orientadas hacia la protección de la persona humana-, que en todo caso deben ser respetados en circunstancias de conflicto armado no internacional. En cuanto tal, constituye como todo el Derecho Internacional Humanitario-, en los términos del artículo 53 de la Convención de Viena sobre el Derecho de los Tratados, una cristalización convencional del ius cogens, de manera que sus preceptivas hacen parte del Derecho Internacional General - derecho consuetudinario- y son de carácter imperativo. No disponibles por acuerdo en contrario ni en denuncian - e imponen obligaciones erga omnes e incondicionales, que tienen como correlato la existencia de derechos no renunciables.

El análisis se podría llamar principio regulador del derecho internacional humanitario en los conflictos armados de carácter interno. El Ministerio Público también considera que es constitucional la posibilidad de desarrollar las normas humanitarias, por medio de acuerdos especiales entre las partes contendientes, tal como lo prevé el artículo 3 común. En efecto, según su criterio y de acuerdo con la Sentencia C-225/95, estos acuerdos no pretenden autorizar transgresiones a los mínimos humanitarios, sino que reconocen que de facto

dichas transgresiones constituyen el pan de cada día, de manera que resulta sensato y acorde con la idea de Humanidad asumir compromisos con énfasis especiales, en la perspectiva de que cada vez sean menos y más restringidos los ámbitos y los tipos de la barbarie.
Esto no significa - aclara el Ministerio Públicoque tales acuerdos sean necesarios ya que ideal ético por alcanzar es "la vigencia incondicional y universal de las normas humanitarias del ius cogens". Sin embargo, un acuerdo especial es no solo "una clara posibilidad jurídica contemplada expresamente por el artículo $3^{\circ}$ común", sino que, además,

se trata de una posibilidad jurídico-política especialmente útil en contextos de negociaciones de paz, en la medida en que contribuye no sólo a aliviar la suerte de las víctimas de la guerra, sino también a favorecer consensos y a acrecentar la confianza recíproca entre los enemigos. ${ }^{34}$

Recuérdese que, en la sentencia objeto de análisis, la Corte Constitucional analizó también el alcance y la constitucionalidad de los acuerdos especiales en el artículo 3 común a los cuatro convenios de Ginebra. Según la tratadista Ana Caterina, dicho análisis "despejó las dudas que pudiesen existir sobre su naturaleza, diciendo que en estricto sentido no son tratados, pues no son celebrados por sujetos de derecho internacional público, sino por sujetos de derecho internacional humanitario" ${ }^{35}$

La argumentación jurídica que sustenta la validez jurídica de las normas humanitarias en la práctica y efectiva del derecho internacional humanitario depende, en gran medida, de que exista una voluntad y un compromiso reales de las partes por respetarlo. ${ }^{36} \mathrm{Lo}$ anterior denota el carácter político que también tiene la celebración de dichos acuerdos. Una cuestión vital en la apreciación que tiene la Corte Constitucional es de concretar que le realización de los acuerdos especiales pueden fortalecer los compromisos entre las partes en conflicto y favorecer la puesta en marcha de mecanismos de verificación, que logren, en la práctica, un creciente cumplimiento de obligaciones humanitarias por las partes enfrentadas. Lo anterior debe sustentarse en la necesidad de que el derecho internacional humanitario tenga una efectiva práctica y no simplemente una validez normativa. ${ }^{37}$

34. Véase Intervención del Ministerio Publico en el análisis de constitucionalidad de la sentencia C-225 de 1995. Pág. 35.

35. Ana Caterina Heyck. Sí Al ACUERdo hUMANITARIO: RAZONES HISTÓRICAS, JURÍDICAS Y POLÍtICAS PARA REALIZARLO. La Silueta. (2004). Pág. 194.

36. Véase Corte Const. Col., supra, nota 5. Acápite 17. [Citado también por Heyck. Pág. 194]

37. Id. Acápite 18. 
El Tribunal Supremo proclama que las normas humanitarias son imperativas y de aplicación inmediata, inclusive manifiesta la honorable Corte:

La obligatoriedad del derecho internacional humanitario se impone a todas las partes que participen en un conflicto armado, y no sólo a las Fuerzas Armadas de aquellos Estados que hayan ratificado los respectivos tratados. No es pues legítimo que un actor armado irregular, o una fuerza armada estatal, consideren que no tienen que respetar en un conflicto armado las normas mínimas de humanidad, por no haber suscrito estos actores los convenios internacionales respectivos, puesto que la fuerza normativa del derecho internacional humanitario deriva de la universal aceptación de sus contenidos normativos por los pueblos civilizados y de la evidencia de los valores de humanidad que estos instrumentos internacionales recogen. ${ }^{38}$

\section{Procedimiento internacional Y LOS SISTEMAS DE PROTECCIÓN DE DERECHOS HUMANOS}

La mayoría de las naciones pertenecientes a la Organización de las Naciones Unidas (ONU) reconocen las normas del derecho internacional humanitario (DIH) como normas vitales de convivencia, entendiendo que, si un Estado ratifica y suscribe los cuatro convenios de Ginebra y sus protocolos adicionales, ese Estado queda obligado a tomar todas las medidas necesarias para aplicar el DIH, ya que este no tiene normas penales que se le puedan aplicar directamente..$^{39}$ La realidad es que, en el mundo, los Estados no cumplían con esa obligación, y que la impunidad se expande y se multiplica, se vio la necesidad de buscar un mecanismo coercitivo y no sólo preventivo. Se pensó entonces en el Tribunal Penal Internacional como una solución para fortalecer efectivamente el DIH. La comunidad internacional se dio cuenta de que la responsabilidad frente al DIH la asumía solamente el Estado, y los individuos que cometían los más infames delitos no eran sancionados o, si lo eran, burlaban la justicia asilándose en algún lugar del mundo. ${ }^{40}$

\section{Id.}

39. Naciones Unidas. Informe de la Alta Comisionada de las NACiOnes Unidas para los Derechos Humanos Sobre la Situación DE los Derechos humanos en Colombia. (Marzo 20 de 2001). Disponible en http://www.hchr.org.co/documentoseinformes/informes/altocomisionado/ informe2000_esp.pdf

40. Marco Sassòli. Responsabilidad del Estado por las violaciones del derecho internacional humanitario. REVISTA INTERNACIONAL DE LA CRUZ
La Comunidad de Naciones quería que se le diera un reconocimiento mundial a los derechos del ser humano sobre el derecho de las naciones de repeler las agresiones de otros Estados y, en general, de grupos armados, y se pensó que esto se lograría internacionalizando la justicia, cerrando el abismo que había entre el derecho interno de cada Estado y el derecho internacional que hasta ahora se había tenido como poco eficaz. ${ }^{41}$

La Comunidad de Naciones busca la vigilancia internacional de los individuos que realicen crímenes de guerra. En el debate del Estatuto de Roma, el cual creó la Corte Penal Internacional, muchos países no apoyaban la creación de esta porque tenían miedo de que esta implicara una disminución de su soberanía, sin entender que la acción de la Corte es subsidiaria. Esto quiere decir que entra en acción sólo cuando los tribunales nacionales están imposibilitados para actuar o no quieren hacerlo, o sea que actúa de manera complementaria a la jurisdicción penal nacional, con lo cual busca respetar el derecho interno, toda vez que el este Estatuto menciona como causal de inadmisibilidad de un asunto que este sea ya objeto de investigación en el Estado, salvo que no esté dispuesto a investigar o continuar investigando los hechos. ${ }^{42}$ Pero para que la Corte entre a actuar es necesaria la firma y ratificación del Tratado por parte de los Estados. Colombia firmó el Tratado y lo ha ratificado por la Ley 742 de 2002, con Sentencia de constitucionalidad C-578 del mismo año, con lo cual constituyó un sistema jurídico de rango supra-

RoJA. Junio 30 de 2009. Disponible en https://www.icrc.org/spa/resources/documents/misc/5tecbx.htm

41. La Cláusula de Martens o Cláusula Martens - llamada así por el diplomático y conspicuo jurista ruso de Martens, quien la formulófigura en el preámbulo del Convenio sobre las Leyes y Costumbres de la Guerra Terrestre adoptado en La Haya el 18 de octubre de 1907. Su texto es el siguiente: "Mientras que se forma un código más completo de las leyes de la guerra, las Altas Partes Contratantes juzgan oportuno declarar que en los casos no comprendidos en las disposiciones reglamentarias adoptadas por ellas las poblaciones y los beligerantes permanecen bajo la garantía y el régimen de los principios del derecho de gentes preconizados por los usos establecidos entre las naciones civilizadas, por las leyes de la humanidad y por las exigencias de la conciencia pública”. De la citada cláusula se infiere que los principios del derecho de gentes se aplican en todo conflicto armado, tanto si una situación dada no se halla prevista por el derecho convencional como si este no vincula, en cuanto tal, a las partes en conflicto. (Véase también Comité Internacional de la Cruz Roja. Comentario del Protocolo del 8 de junio de 1977 adicional a los Convenios de Ginebra del 12 de agosto de 1949, relativo a la protección de las víctimas de los conflictos armados internacionales, párr. 56).

42. Leonardo Franco. Interpretación y aplicabilidad del derecho internacional humanitario por la Corte Interamericana de Derechos Humanos. Estudio de Derecho Internacional Humanitario ConsuetudiNARIO. Marzo 7 de 2008. Disponible en https://www.icrc.org/spa/assets/ files/other/ icrc_003_t2009106.pdf 
nacional de carácter permanente e independiente que permite la investigación, la persecución y el castigo de aquellos delitos que, por su naturaleza, se consideran un atentado grave contra la totalidad del género humano. ${ }^{43}$ Dando así competencia a la Corte para conocer las conductas tipificadas en el Estatuto como violatorias del DIH y que hayan sido realizadas en Colombia como Estado parte, pero sin dejar a un lado el deber de todo Estado de ejercer su jurisdicción penal contra los responsables de esta clase de violaciones. En cuanto a la competencia de la Corte, esta no es retroactiva en principio, se aplica sólo a crímenes cometidos después de la entrada en vigor del Estatuto, salvo que el Estado que ratifica disponga lo contrario.

Los tipos de delitos en los que la Corte tiene competencia son los siguientes: crímenes de genocidio, crímenes de lesa humanidad, crímenes de guerra y delito de agresión. ${ }^{44}$ Estos delitos están ampliamente definidos en el articulado del Estatuto, y de esto se encargaron algunas organizaciones no gubernamentales, las cuales lograron que se definieran e incluyeran en el Estatuto las agresiones sexuales tan comúnmente realizadas en los conflictos armados, como violación, embarazo forzado, esclavitud sexual, prostitución forzada, esterilización forzada y otros de gravedad similar. ${ }^{45}$ En cuanto al crimen de agresión, este no fue definido en el Estatuto y algunos entes, como el Comité Internacional de la Cruz Roja, acuden a la definición hecha por las $\mathrm{Na}$ ciones Unidas.

Existen tres formas para que la Corte Penal Internacional entre a ejercer su jurisdicción: ${ }^{46}$

- El fiscal de oficio inicia la investigación de un hecho y luego lo denuncia a la Corte.

- El fiscal por denuncia del Consejo de Seguridad realiza una investigación.

- Un Estado denuncia una situación que pareciera ser de competencia de la Corte y se la remite al fiscal para que asuma el conocimiento. La Fiscalía es un órgano separado de ella, que actúa de forma independiente y, cuando llega a la conclusión de que

\footnotetext{
43. E. g. Carlos Parra Dussán. El marco para la paz desde el Estatuto de Roma. La República. Disponible en http://www.larepublica.co/asuntoslegales/el-marco-para-la-paz-desde-el-estatuto-de-roma_52131

44. Id.

45. Comisión Interamericana de Derechos Humanos [CIDH]. InForme sobre Seguridad Ciudadana y Derechos Humanos. (Diciembre 31 de 2009). Disponible en https://www.oas.org/es/cidh/docs/pdfs/ SEGURIDAD\%20CIUDADANA\%202009\%20ESP.pdf

46. Véase www.sinu.org.mx/temas/drinf/cpi.htm
}

existen fundamentos suficientes para acusar, acude a la Sala de Cuestiones Preliminares de la Corte para que esta pueda actuar. Esto hace que la Corte actúe de manera eficaz e independiente.

La Corte es la que tiene competencia respecto de personas naturales, las cuales serán responsables individualmente y podrán ser penalizadas de acuerdo con el Estatuto. La Corte no será competente respecto de los menores de 18 años. Es tan vital esa competencia sobre el individuo que la obediencia debida no exime de la responsabilidad penal individual, y son ilícitas las órdenes de cometer crímenes de lesa humanidad o genocidio. La Corte es un instrumento vital contra la impunidad y contra la injusticia, ya que, si se establecen responsabilidades individuales y no solo estatales, se hará justicia y se logrará tener una paz internacional.

La Constitución de 1991, por último, reorganizó las instituciones para que puedan ser eficientes y eficaces. Un Estado sin estas calidades resulta igualmente ilegítimo, pues todas las promesas se convierten en meras ilusiones. Se reformó la administración de justicia y se creó la Corte Constitucional, el Consejo Superior de la Judicatura y la Fiscalía General de la Nación. Se pasó al sistema acusatorio y se definió la organización autónoma y desconcentrada de la justicia.

Una violación de derechos humanos significa que el Estado está incumpliendo uno de los requisitos a los que se hizo parte al haber ratificado la Convención Americana sobre Derechos Humanos, ${ }^{47}$ como es respetar los derechos consagrados y no haber garantizado su libre y pleno ejercicio, y el Estado podrá ser condenado internacionalmente, debido a que esta convención sobre derechos humanos hace parte del bloque de constitucionalidad.

El marco del protocolo II de Ginebra denota que la responsabilidad de los Estados consiste en una violación de alguna de las obligaciones establecidas en los instrumentos suscritos dentro del sistema. Los Estados, parte de la Convención Americana, como es el caso de Colombia, deben respetar las obligaciones contenidas en ella, ya que, de lo contrario, pueden ver comprometida

47. Para la ratificación de un tratado internacional, en Colombia se sigue un proceso complejo que involucra la participación de los tres poderes públicos. Así, el tratado primero debe contar con una ley aprobatoria expedida por el poder legislativo en cabeza del Congreso de la República, la cual debe ser sancionada por el ejecutivo en cabeza del presidente de la República y seis días después debe ser enviada para la revisión constitucional por parte del poder judicial, en cabeza de la Corte Constitucional. 
su responsabilidad internacional. Las permanentes violaciones a los derechos del hombre son características evidentes del conflicto colombiano, el cual hace parte de la cotidianidad de una guerra. ${ }^{48}$ Este tipo de conflictos está regulado por la normativa producto de la Convención de Ginebra. Los convenios de Ginebra constituyen una serie de normas internacionales para "humanizar la guerra", como dice Ramelli, puesto que las permanentes violaciones a los derechos del hombre son características evidentes del conflicto colombiano, conflicto que hace parte de la cotidianidad de una guerra que irrumpe en las actividades diarias de destrucción y muerte.

Los convenios de Ginebra constituyen una serie de normas internacionales para "humanizar la guerra". El problema consiste en que, de vez en cuando, los hombres armados eligen con cuidado a sus víctimas con listas en mano. En este sentido, con el presente análisis jurídico, se pretende llenar esa laguna de conocimiento sobre este tema, mostrando las falencias en la aplicación de estas normas en nuestro país.

La Constitución colombiana consagra tantos y amplios derechos que hace que pueda contarse entre las más completas y actualizadas. Con ella fueron corregidas la imperdonables omisiones del constituyente a lo largo del siglo XX, que se conformó siempre con la enunciación teórica de los derecho civiles y las garantías sociales que ocupaban el título III de la Constitución de $1886^{49}$ y que resultaban tan formales, dentro de la concepción entonces dominante, "que para darles validez y alguna efectividad fue necesario que se ordenara incluirlos en el texto del Código Civil, como Título Preliminar, como si no hubiese sido suficiente su reconocimiento en el Estatuto Fundamental". ${ }^{50}$ En la Carta Magna de 1991, a partir del preámbulo, cuya fuerza vinculante ha sido reconocido explícitamente por la Corte Constitucional, ha quedado claro que la base misma del sistema jurídico tiene por propósito asegu-

48. Para acuerdos especiales o humanitarios, documento sobre DIH y algunas propuestas para la humanización del conflicto armado colombiano, véase www.colectivodeabogados.org

49. Obviamente esto no añadía nada a su fuerza, pues en virtud de esta disposición no se elevaba el título III a una categoría superior, sino que, por el contrario, se le colocaba en una norma de rango inferior [...] en teoría la Constitución era ley suprema, pero los jueces podían aplicar solamente la ley, no la Constitución; así entonces, para dar efectividad práctica a los derechos civiles y garantías sociales consagrados en la Constitución era el caso incorporar tales disposiciones a la legislación ordinaria con base en las cuales debían producirse los pronunciamientos judiciales.

50. José Gregorio Hernández Galindo. Colombia ante la Corte Interamericana de Derechos Humanos. Editorial Ibáñez. (2006). Pág. 22. rar los valores de la vida, la convivencia, el trabajo, la justicia, la igualdad, el conocimiento, la libertad y la paz, y que ello se hace en desarrollo de unos principios fundamentales y dentro del esquema de un orden político, económico y social justo.

La Sentencia C-771 del 2011 establece que el derecho a la justicia implica el deber del Estado de investigar todos los casos de grave violación de los derechos humanos y de sancionar a sus responsables con penas adecuadas y proporcionadas a la gravedad de sus acciones. ${ }^{51}$ Ya que la Corte se refirió a los derechos derivados de la condición de desplazado forzado en cuanto derecho a la justicia, se debe entender que este delito no debe quedar impune. ${ }^{52} \mathrm{~A}$ pesar de ser un tema recurrente, debido a la presencia de un conflicto armado interno, en realidad sus pronunciamientos no han sido muchos, pero sí contundentes.

Uno de los casos que mayor claridad aporta al debate sobre el derecho a la justicia se encuentra en la Sentencia C-578 del 2002, ${ }^{53}$ que estudió la constitucionalidad del Estatuto de la Corte Penal Internacional. Pero la Corte Constitucional reconoció que el derecho internacional ha considerado que los instrumentos internos, utilizados por los Estados para lograr la reconciliación, deben garantizar a las víctimas y perjudicados de una conducta criminal la posibilidad de acceder a la justicia, para conocer la verdad sobre lo ocurrido y obtener una protección judicial efectiva. ${ }^{54}$ Se puede dar esta posibilidad si un organismo internacional de derechos humanos, aceptado por Colombia, constata un incumplimiento de las obligaciones del Estado colombiano de investigar conductas violatorias del derecho internacional de los derechos humanos, ${ }^{55} \mathrm{O}$ del DiH, ${ }^{56}$ caso en el cual es posible revisar las decisio-

51. Corte Constitucional de Colombia. Sentencia C-771/11. (Octubre 03 de 2011). Disponible en http://www.corteconstitucional.gov.co/ relatoria/2011/c-771-11.htm

52. Corte Constitucional de Colombia. Sentencia T-327/01. (Marzo 26 de 2001). Disponible en http://www.corteconstitucional.gov.co/ relatoria/2001/t-327-01.htm

53. Corte Constitucional de Colombia. Sentencia C-578/o2. (Julio 30 de 2002). Disponible en http://www.corteconstitucional.gov.co/ relatoria/2002/c-578-02.htm

54. Expediente LAT-223. Revisión de LA Ley 742 Del 5 de JUnio de 2002, por medio de la cual se aprueba el Estatuto De Roma De La Corte Penal Internacional. (M. P. Manuel José Cepeda Espinosa: julio 17 de 1998).

55. El DIDH dispone acerca de aspectos de la vida en tiempo de paz que no están reglamentados por el DIH, como la libertad de prensa, el derecho a reunirse, a votar y a declararse en huelga.

56. El DIH contiene disposiciones sobre muchas cuestiones que están por fuera del ámbito del DIDH, como la conducción de las hostilidades, 
nes absolutorias nacionales que produjeron una situación de impunidad. ${ }^{57}$

La Corte Constitucional ha reconocido la vigencia del principio de jurisdicción universal y ha afirmado que

el principio de jurisdicción universal, que atribuye a todos los estados del mundo la facultad de asumir competencia sobre quienes cometan ciertos delitos que han sido especialmente condenados por la comunidad internacional, tales como el genocidio, la tortura o el terrorismo, siempre que tales personas se encuentren en su territorio nacional, aunque el hecho no haya sido cometido allí $[\ldots]$ opera cuando consta en un tratado. ${ }^{58}$

En el ámbito de los sistemas internacionales de protección de derechos humanos, como el Sistema Interamericano de Derechos Humanos de la Organización de Estados Americanos y el Sistema Universal de las Naciones Unidas, el Estado colombiano responde internacionalmente, ya sea por acción u omisión de agentes estatales que violen los derechos consagrados en los tratados internacionales de derechos humanos ratificados por el Estado colombiano y con cláusula de competencia para los órganos que los conforman. Los sistemas internacionales de protección de derechos humanos analizan exclusivamente la responsabilidad internacional del Estado, y no se realiza ningún juicio o consideración respecto de la responsabilidad penal individual.

Botero y Restrepo anotan que el derecho internacional de los derechos humanos se manifiesta en cuatro aspectos relevantes:

[...] en las obligaciones de los estados en materia de defensa y garantía de los derechos humanos, (ii) en el establecimiento de la responsabilidad penal individual por la comisión de graves violaciones a los derechos humanos o al derecho internacional humanitario, (iii) en la ampliación y fortalecimiento de los mecanismos internacionales de garantía del cumplimiento de las

los estatutos de combatiente y de prisionero de guerra y la protección del emblema de la Cruz Roja y de la medialuna roja.

57. Corte Constitucional de Colombia. Sentencia C-oo4/o3. (Enero 20 de 2003). Disponible en http://www.corteconstitucional.gov.co/ relatoria/2003/c-004-03.htm

58. Corte Constitucional de Colombia. Sentencia C-1189/oo. (Septiembre 13 de 2000). Disponible en http://www.corteconstitucional.gov. co/relatoria/2000/c-1189-00.htm y Sentencia C-554/01. (Mayo 05 de 2001). Disponible en http://www.alcaldiabogota.gov.co/sisjur/normas/ Norma1.jsp?i=44256 obligaciones internacionales de los estados (en materia de derechos humanos y Derecho Internacional Humanitario) y, finalmente, (iv) en la extensión de la protección internacional de los derechos humanos de tiempos de paz a tiempos de guerra y de tiempos de guerra a tiempos de transición. ${ }^{59}$

Uno de estos aspectos se ve reflejado en cuatro cuerpos del derecho internacional público: el derecho internacional de los derechos humanos, el derecho internacional humanitario, el derecho penal internacional y el emergente derecho internacional antiterrorista. ${ }^{60}$ Pero también se ha presentado el fortalecimiento del derecho interno de protección a la persona humana, aplicando el protocolo II de Ginebra en correlación a los estándares internacionales de derechos humanos, ya que el DIH es un conjunto de normas que, por razones humanitarias, trata de limitar los efectos de los conflictos armados, para proteger a las personas que no participan o que ya no hacen parte de los combates que limitan los medios y los métodos para hacer la guerra. También suele llamarse como "derecho de la guerra", de aquí que el DiH se conforme de tratados o convenios que deben cumplir los Estados que se han suscrito a ellos.

El DIH tiene dos clasificaciones básicas: el derecho de Ginebra y el de La Haya. El primero de ellos, el derecho de Ginebra, hace referencia a las normas relativas a la protección y respeto del ser humano en situaciones de conflicto armado. El DIH también llamado derecho de los conflictos armados o derecho de la guerra tiene por objeto el alivio del sufrimiento, en términos psicológicos, de las víctimas, regulando lo pertinente a la guerra, así como poner límite a los métodos y medios de hacer la guerra. Sobre el derecho a la justicia, es clara la obligación internacional de Colombia de investigar, juzgar y condenar a penas adecuadas a responsables de violaciones graves a los derechos humanos.

La claridad de estas obligaciones tiene sustento en el Sistema Interamericano de Derechos Humanos (artículos xviII y xxiv de la Declaración Americana de Derechos Humanos, y artículos 1-1, 2, ${ }^{61} 8$ y 25 de la

59. Catalina Botero Marino y Esteban Restrepo Saldarriaga. Estándares internacionales y procesos de transición en Colombia. Comp. Angelika Rettberg. ENTRE EL PERDóN Y EL PAREDÓN: PREGUNTAS Y DILEMAS DE LA JUSTICIA TRANSICIONAL. Ediciones Uniandes. (2005).

60. Véase Uprimny, supra, nota 31.

61. Si el ejercicio de los derechos y libertades mencionados en el artículo 1 no estuviere ya garantizado por disposiciones legislativas o de otro carácter, los Estados partes se comprometen a adoptar, con arreglo a sus procedimientos constitucionales y a las disposiciones de esta conven- 
Convención Americana sobre Derechos Humanos), en el DIH (los cuatro convenios de Ginebra, de 1949, y el primer protocolo adicional a estos, Convenio I, artículo 49; Convenio II, artículo 50; Convenio III, artículo 146; Protocolo I, artículo 85). Y, por supuesto, mediante la aplicabilidad del Protocolo II de Ginebra. Además, la Corte Penal Internacional establece los límites que ya se han mencionado y que en Colombia han sido desarrollados por la jurisprudencia constitucional.

\section{CONCLUSIONES}

Las políticas democráticas y la lucha por la vigencia de los derechos humanos en Colombia han sido vulneradas - aunque, por fortuna, no derrotadas- por la delincuencia del narcotráfico, sus alianzas con los grupos terroristas de derecha y de izquierda y su activa presencia en las zonas marginales de las grandes ciudades. Esta alianza ha producido el homicidio calculado y siniestro de los líderes de las nuevas fuerzas políticas de izquierda y de dirigentes locales de los partidos tradicionales de centro y de izquierda democrática. De esta situación, un sector evidentemente minoritario de agentes del Estado ha incurrido en acciones delictivas que desvirtúan el sentido de la investidura del poder. Paralelamente, los grupos insurgentes agrupados en guerrillas de todas las tendencias ideológicas recurren al terrorismo contra la población civil y las unidades militares, con el uso complementario de formas de financiamiento derivadas del secuestro y la extorsión. Causa de esta situación, son tres personas diarias víctimas de las minas antipersonales, que en el $65 \%$ de los casos son militares y el resto civiles (se calcula que cae un niño cada diez días). Normalmente, las víctimas son campesinos de zonas apartadas.

Las variadas formas de violencia que se presentan en Colombia imponen la necesidad de revisar los conceptos tradicionales relacionados con las fuentes de violación de derechos humanos, la manera para eximir al Estado y sus agentes de su función fundamental de respetarlos y garantizarlos, en una perspectiva que permita ampliar las dimensiones de su defensa y de su protección. En este sentido, ya la comunidad interna-

ción, las medidas legislativas o de otro carácter que fueren necesarias para hacer efectivos tales derechos y libertades. cional comienza a preocuparse y a expresar puntos de vista coincidentes.

La interpretación de estos deberes del Estado debe partir de la obligación de prevención. Esta abarca todas aquellas medidas de carácter jurídico, político, administrativo y cultural que promuevan la salvaguarda de los derechos humanos y que aseguren que las eventuales violaciones sean efectivamente consideradas y tratadas como un hecho ilícito, que es susceptible de acarrear sanciones para quien las comete, así como la obligación de indemnizar a las víctimas. La obligación de prevenir es de medio y no se demuestra su incumplimiento por el solo hecho de que un derecho haya sido violado, pero es indiscutible que el derecho a la justicia (investigar, sancionar y reparar) se trata como una unidad dentro del sistema y, por tanto, la negación de alguno de los elementos mencionados significa no sólo la negación de los derechos directamente reconocidos.

\section{REFERENCIAS}

Alejandro Ramelli Arteaga. Derecho internacional humanitario y estado de beligerancia. Serie de Teoría Jurídica y Filosofía del Derecho, 12. Universidad Externado de Colombia. (2001).

Alejandro Ramelli Arteaga. La Constitución colombiana y el derecho internacional humanitario. 2. ${ }^{a}$ Ed. Universidad Externado de Colombia. (2003).

Ana Caterina Heyck. Sí AL ACUerdo humanitario: RAZONES HISTÓRICAS, JURÍDICAS Y POLÍTICAS PARA REALIZARLO. La Silueta. (2004).

Antonio Truyol y Serra. FundaMentos DEL DERECHO INTERNACIONAL PÚblico. 4.a Ed. Editorial Tecnos. (1977).

Carlos Parra Dussán. El marco para la paz desde el Estatuto de Roma. La República. Disponible en http://www. larepublica.co/asuntos-legales/el-marco-para-la-pazdesde-el-estatuto-de-roma_52131

Catalina Botero Marino y Esteban Restrepo Saldarriaga. Estándares internacionales y procesos de transición en Colombia. Comp. Angelika Rettberg. Entre el Perdón Y EL PAREDÓN: PREGUNTAS Y DILEMAS DE LA JUSTICIA TRANSICIONAL. Ediciones Uniandes. (2005).

Comisión Interamericana de Derechos Humanos [CIDH] Informe sobre Seguridad CiUdadana y Derechos Humanos. (Diciembre 31 de 2009). Disponible en https://www.oas.org/es/cidh/docs/pdfs/SEGURIDAD\%20CIUDADANA\%202009\%20ESP.pdf 
Consultoría para los Derechos Humanos y el Desplazamiento (Codhes). Conferencia Regional Humanitaria (CRH) sobre la Protección de Personas DesplaZADAS Y REFUGIADAS. Quito. (2010).

Consultoría para los Derechos Humanos y el Desplazamiento (Codhes). Un País QUe HUYE: DESPlazamiento Y VIOLENCIA EN UNA NACIÓN FRAGMENTADA. Codhes Unicef Colombia. (1999). Consultado el 12 de agosto de 2014 en http://www.acnur.org/biblioteca/pdf/5161. pdf?view $=1$

Corte Constitucional de Colombia. Sentencia No. T-002/92. (Mayo 8 de 1992). Disponible en http://www.corteconstitucional.gov.co/relatoria/1992/t-002-92.htm\#_ftn6

Corte Constitucional de Colombia. Sentencia C-170/95. (Abril 20 de 1995). Disponible en http://www.corteconstitucional.gov.co/relatoria/1995/C-170-95.htm

Corte Constitucional de Colombia. Sentencia C-225/95. (Mayo 8 de 1995). Disponible en www.corteconstitucional. gov.co/relatoria/1995/c-225-95.htm

Corte Constitucional de Colombia. Sentencia C-1189/oo. (Septiembre 13 de 2000). Disponible en http://www. corteconstitucional.gov.co/relatoria/2000/c-1189-00. htm

Corte Constitucional de Colombia. Sentencia T-327/01. (Marzo 26 de 2001). Disponible en http://www.corteconstitucional.gov.co/relatoria/2001/t-327-01.htm

Corte Constitucional de Colombia. Sentencia C-554/o1. (Mayo 05 de 2001). Disponible en http://www.alcaldiabogota.gov.co/sisjur/normas/Norma1.jsp?i=44256

Corte Constitucional de Colombia. Sentencia C-578/02. (Julio 30 de 2002). Disponible en http://www.corteconstitucional.gov.co/relatoria/2002/c-578-02.htm

Corte Constitucional de Colombia. Sentencia C-004/03. (Enero 20 de 2003). Disponible en http://www.corteconstitucional.gov.co/relatoria/2003/c-004-03.htm

Corte Constitucional de Colombia. Sentencia T-708/03. (Agosto 14 de 2003). Disponible en http://www.corteconstitucional.gov.co/relatoria/2003/T-708-03.htm

Corte Constitucional de Colombia. Sentencia C-771/11. (Octubre 03 de 2011). Disponible en http://www.corteconstitucional.gov.co/relatoria/2011/c-771-11.htm

Corte Interamericana de Derechos Humanos. Sentencia DEL 8 DE MARZo de 1998 (Fondo). CASO de la "PANEL Blanca” (Paniagua Morales y otros) Vs. GuateMALA. (8 de marzo de 1998). Disponible en http://www. corteidh.or.cr/docs/casos/articulos/seriec_37_esp.pdf

EXPediente LAT-223. Revisión DE LA LeY 742 DEL 5 DE JUNIO DE 2002, POR MEDIO DE LA CUAL SE APRUEBA EL Estatuto De Roma De la Corte Penal Interna-
CIONAL. (M. P. Manuel José Cepeda Espinosa: julio 17 de 1998).

Fiscalía General de la Nación. Decisión de la Fiscalía 49 ESPECIALIZADA UNDH - DIH CALIFICANDO DE CRIMEN CONTRA LA HUMANIDAD EL SECUESTRO DE JINETH Bedoya. Septiembre 10 de 2012.

http://www.colectivodeabogados.org/ (Enero 15 enero de 2008).

Jean Pictet. Desarrollo y PRINCIPIOS DEL DeReCho INTERnACIONAL humanitario. Instituto Henry Dunant. (1986). Pág. 74.

José Gregorio Hernández Galindo. Colombia ANTE LA CoRte Interamericana de Derechos Humanos. Editorial Ibáñez. (2006).

Leonardo Franco. Interpretación y aplicabilidad del derecho internacional humanitario por la Corte Interamericana de Derechos Humanos. Estudio de Derecho Internacional Humanitario Consuetudinario. Marzo 7 de 2008. Disponible en https://www.icrc.org/spa/assets/ files/other/icrc_003_t2009106.pdf

Ley 32 de 1985. Por la cual se aprueba la Convención de Viena sobre el Derecho de los Tratados. Febrero 13 de 1985. DO N. ${ }^{\circ} 36.856$.

Ley 288 de 1996. Por medio de la cual se establecen instrumentos para la indemnización de perjuicio a las víctimas de violaciones de derechos humanos en virtud de lo dispuesto por determinados órganos internacionales de Derechos Humanos. Julio 05 del 1996. DO N. ${ }^{\circ} 42826$ de julio 09 de 1996.

Libardo Orejuela Díaz. Derechos humanos. La tragedia DeSde UNA LeCtura amable. Ediciones Universidad Libre. (2002).

Loretta Ortiz Ahlf. Derecho internacional público. UNAM - Harla. (1988).

Louis Favoreu y Francisco Rubio Llorente. EL BLOQUE DE CONSTITUCIONALIDAD. Civitas. (1991)

Marco Sassòli. Responsabilidad del Estado por las violaciones del derecho internacional humanitario. Revista InTERnACiONAL DE LA CRUz Roja. Junio 30 de 2009. Disponible en https://www.icrc.org/spa/resources/documents/misc/5tecbx.htm

Manuel Cepeda. Los Derechos fundamentales EN LA Constitución de 1991. Editorial Temis S. A. (1997).

Naciones Unidas. Preámbulo. Carta de las Naciones UniDAS. 1945. Disponible en http://www.un.org/es/documents/charter/preamble.shtml

Naciones Unidas. Convención de Viena sobre el DereCho de los Tratados. (Mayo 23 de 1969). 
Naciones Unidas. Informe de la Alta Comisionada de LAS NaCiones Unidas Para los Derechos Humanos SOBRE LA SITUACIÓN DE LOS DERECHOS HUMANOS EN Colombia. (Marzo 20 de 2001). Disponible en http:// www.hchr.org.co/ documentoseinformes/informes/altocomisionado/informe2000_esp.pdf

Ramón Pacheco Sánchez. InTERrelación ENTre NORMAS DEL DERECHO INTERNACIONAL PÚBLICO Y EL DERECHO INTERNo. Estatus PREVAlente DE NORMA IUS
CONGENS. (Febrero 26 de 2012). Disponible en http:// derechointernacionaluniversidadlibre.blogspot. com/2012/02/interrelacion-entre-normas-del-derecho.html

Rodrigo Uprimny Yepes. El bloque de constitucionalidad en Colombia. Un análisis jurisprudencial y un ensayo de sistematización doctrinal. Dejusticia. Diciembre 12 de 2005. Disponible en http://www.dejusticia.org/files/ r2_actividades_recursos/ fi_name_recurso.46.pdf 